\title{
Who tended to continue smoking after cancer diagnosis: the national health and nutrition examination survey 1999-2008
}

\author{
Tung-Sung Tseng ${ }^{1 *}$, Hui-Yi Lin², Sarah Moody-Thomas ${ }^{1}$, Michelle Martin ${ }^{3}$ and Ted Chen ${ }^{4}$
}

\begin{abstract}
Background: It has been estimated that there are approximately 12 million cancer survivors in the United States. Continued smoking after a cancer diagnosis is linked to adverse effects among cancer survivors on overall survival, treatment effectiveness, and quality of life. Little is known about who is more likely to quit smoking after his/her cancer diagnosis. The objective of this study is to evaluate factors associated with smoking cessation in cancer survivors, which to date has not been well studied.

Method: The National Health and Nutrition Examination Survey (NHANES) 1999-2008 surveys were used in this study. A total of 2,374 cancer survivors aged 20 and over with valid smoking status in the NHANES 99-08 survey were included in this study. Among them, 566 cancer survivors who regularly smoked at the time of their cancer diagnosis were included in the analyses.

Results: Around $50.6 \%$ of cancer survivors smoked regularly prior to their cancer diagnosis and only $36.1 \%$ of them quit smoking after their cancer diagnosis. Racial disparity was observed in smoking cessation among cancer survivors. Hispanics $(\mathrm{OR}=0.23,95 \% \mathrm{Cl}=0.10-0.57)$ were less likely to quit smoking than Whites after their cancer diagnosis.

Conclusion: Two-thirds of cancer survivors continued smoking after cancer diagnosis. Our study observed that the high risk group of continued smokers among cancer survivors is made up of those who are female, younger, Hispanic, with longer smoking history, underweight or with normal weight and without smoking-related cancer. These findings suggest that smoking cessation for cancer survivors should target on the high risk subgroups.
\end{abstract}

Keywords: Cancer survivor, Tobacco control, Disparity

\section{Background}

Smoking cessation among cancer survivors has become an important issue while survival rates improve as treatment and health care improve. Survival rates for all cancers combined have improved over the past three decades. It has been estimated that there are 12 million cancer survivors in the United States, representing nearly $4 \%$ of the entire US population $[1,2]$. As early detection and treatment improve, the number of survivors and their length of survival are expected to increase. In 1971, long term survival rates were $<50 \%$ [3]. Today,

\footnotetext{
* Correspondence: ttseng@lsuhsc.edu

${ }^{1}$ School of Public Health, Louisiana State University Health Sciences Center, 2020 Gravier Street, New Orleans, LA 70112, USA

Full list of author information is available at the end of the article
}

$64 \%$ of persons diagnosed with cancer expect to be alive in five years with five year survival rates for early stage colorectal, breast, and prostate cancers exceeding $90 \%$ [4]. About $60 \%$ of cancer survivors were aged 65 or older. This increased life expectancy puts cancer survivors at greater risk for second malignancies, co-morbid conditions, and other chronic illnesses [5,6]. Several health-related risk behaviors including tobacco use, alcohol use, physical activity, diet and weight control [5,7-10] among cancer survivors have been recently discussed. Smoking influences cancer prognosis [5]. Thus, it may be of particular interest to understand quitting behavior among cancer survivors. 


\section{Smoking and cancer survivors}

The current smoking rate among cancer survivors and the quit rate after cancer diagnosis illustrate the need for improvement in smoking cessation among cancer survivors. The prevalence of smoking among cancer survivors varies by cancer type [11-14]. For example, Coups et al. used data from the National Health Interview Survey (NHIS) 2000 to examine the prevalence of smoking among 1646 cancer survivors. In this study, the current smoking rate for cervical cancer survivors (46\%) was higher than the rate observed in survivors of other types of cancer such as uterine (29.4\%), melanoma (13.0\%), breast (14.1\%), prostate (5.5\%) and colon (12.2\%) cancer [15]. Age is an important factor when evaluating the differences in age-adjusted smoking rates for specific cancer sub-groups. Tseng et al., using data from National Health and Nutrition Examination Survey (NHANES 1999-2008), found that after adjusting for age based on the 2000 U.S. Census population, the cervical, colon and melanoma cancer survivors had the highest age-adjusted smoking rates $(42.9 \%, 46.2 \%$ and $32.1 \%$, respectively). Individuals with breast, non-melanoma skin, lung/larynx/windpipe, and prostate cancer had lower ageadjusted smoking rates $(9.5 \%, 12.6 \%, 13.1 \%$, and $20.9 \%$, respectively) [14]. Cancer survivors who continue to smoke after diagnosis experience adverse impacts on cancer treatment effectiveness, more complications, lower survival rates, more comorbidity and poorer quality of life than patients who stop smoking before or at the time of diagnosis [8,16-18]. In addition, smoking is well known to be associated with some second malignancies and most chronic diseases [19]. Although there are some successful smoking cessation approaches and guidelines are available to cancer patients [20], about $50 \%$ of smoking cancer survivors who smoke continue to smoke after diagnosis with cancer [16,21]. Thus, smoking cessation should be considered an important part of improved cancer treatment and survival rates.

In order to design effective smoking cessation interventions for cancer survivors, it is important to know the timing, mediating factors and the target group that would optimize effects from smoking cessation programs. Timing and synthetic effect with other risk behaviors are also important issues for successful smoking cessation among cancer survivors. Grize et al. suggested that a cancer diagnosis could be a teachable moment for smoking cessation [16]. A study also showed that a personal diagnosis of cancer, or a diagnosis in a family member or friend, may have acted as a 'cue to action' to improve lifestyle health behaviors [22]. Butterfield et al. also found that the majority $(63 \%)$ of cancer survivors who smoke are likely to engage in multiple unhealthful lifestyle behaviors [23]. However, little is known about who is more likely to quit smoking after his/her cancer diagnosis, and how to develop an integrated approach for smoking cessation intervention.

Because most clinical trials do not assess smoking status or only collect limited information about smoking status such as current, former, or never smoker status and do not control for health status, comorbidity, timing or other risky or healthy behaviors such as alcohol use, physical activity, BMI, or utilization of health care, it is important to explore more about smoking cessation behavior among cancer survivors. This study is designed to examine the factors associated with quit smoking among cancer survivors and to explore how soon they will quit after cancer diagnosis. Also, many studies have utilized relatively small samples, which might result in selection bias and lack of diversity in socioeconomic background. In this study, we used national data with a diverse population to analyze quit smoking behavior among cancer survivors. The objectives of this study were to (1) examine quit smoking behaviors after cancer diagnosis; (2) evaluate factors associated with this quit smoking behavior using The National Health and Nutrition Examination Survey (NHANES) 1999-2008 data.

\section{Methods}

\section{Study population}

We used the National Health and Nutrition Examination Survey (NHANES) 1999-2008 survey, which combined five data sets of 2-year cycles (1999-2000, 2001-2002, 2003-2004, 2005-2006, and 2007-0008). The NHANES, initiated by the Centers for Disease Control and Prevention (CDC) and National Center for Health Statistics (NCHS), is a population-based survey that assesses the health and nutritional status in the United States. The introduction and data collection for the NHANES have been described previously [24]. Cancer survivors were identified based on the question: "Have you ever been told by a doctor or other health professional that you had cancer or a malignancy of any kind?" For those who had multiple cancers, the time of first cancer diagnosis was applied to define the primary outcome, quit smoking status at cancer diagnosis. The impact of combined cancer types (smoking and non-smoking related cancer), defined based on the American Cancer Society's classification [25], was evaluated. The former smokers, who smoked at least 100 cigarettes in life or who had ever smoked regularly and reported not smoking at the interview time, were considered as having quit smoking. For these former smokers, the question "How long has it been since you quit smoking cigarettes" was given. Based on this question, age of quitting smoking could be obtained. The time intervals between first cancer diagnosis and quit smoking were calculated by subtracting the age of these two events. Using these time intervals, we could identify who quitted smoking after cancer 
diagnosis. As seen in Figure 1, a total of 566 cancer survivors aged 20 or older who smoked more than 100 cigarettes during their lifetimes and smoked regularly before or at the time of cancer diagnosis were included in our primary analyses.

\section{Statistical analyses}

Descriptive statistics of the demographic and behavioral characteristics were presented by quit smoking status after cancer diagnosis. The differences of these characteristics between cancer survivors who quit and those who did not quit smoking after cancer diagnosis were evaluated using the Rao-Scott chi-square with an adjusted $\mathrm{F}$ statistic for categorical variables and the $t$-test for continuous variables. The income level was measured using a poverty income ratio: total family income to family's poverty threshold, which is family size adjusted. Individuals in a family with the poverty income ratio less than 1 were considered poor. Behavioral characteristics included physical activity, alcohol use, selfimage of weight and weight control intention.

We included basic demographic variables (Table 1), cancer, smoking, body weight, health behaviors, health status related factors (Table 2) in the analyses. In order to evaluate factors associated with quit smoking after cancer diagnosis, a logistic regression model with the appropriate sampling weights was applied (using Proc Surveylogistic in SAS). The outcome variable was quit smoking status. Both univariate and multivariable analyses were performed. The stepwise variable selections with a p-value of 0.05 as entry and removal criteria were applied in order to determine a parsimonious final model. We forced age and gender in the model, and other candidate variables included race, education, poverty income ratio, marital status, cancer year, smokingrelated cancer, smoking year, BMI, vigorous activity over past 30 days, days of $\geq 5$ drinks in 12 months, disease number and health care times over past year. The factors that were highly correlated with each other were excluded. For example, smoking initiation age and first cancer diagnosis age were not included in the model because these two variables were used to define smoking year and cancer year. BMI was highly associated with self-image of weight ( $p$ value $<0.0001$ ) so only objective BMI measurements were included in the model. The adjusted odds ratios (ORs) and the corresponding 95\% confidence intervals (CIs) of these factors were calculated. All analyses were weighted to account for the

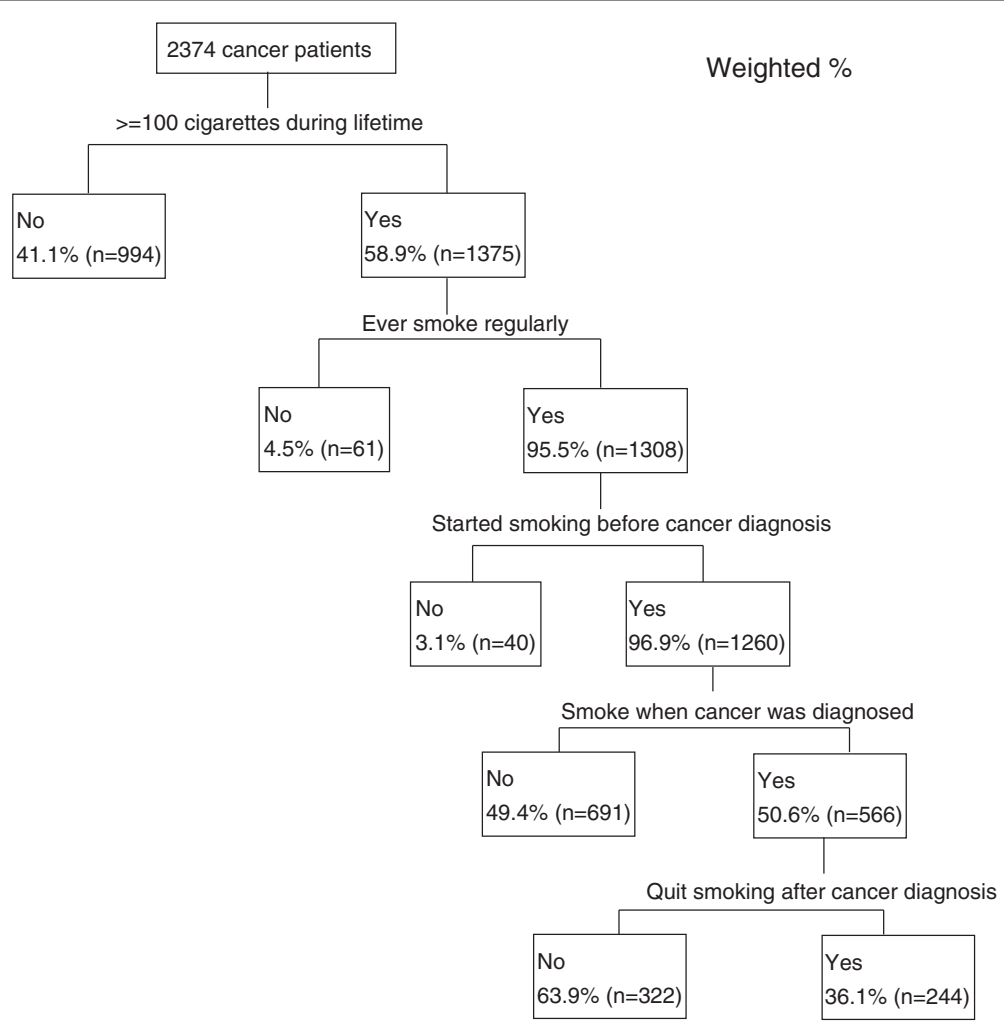

Figure 1 Diagram of data analysis from NHANES 99-08. 
Table 1 Demographic characteristics of 566 cancer survivors who regularly smoke prior to cancer diagnosis using the NHANES 99-08 data

\begin{tabular}{|c|c|c|c|}
\hline Characteristic & $\begin{array}{l}\text { Quit }(n=244) \\
N(\text { weighted\%) }\end{array}$ & $\begin{array}{l}\text { Not quit }(n=322) \\
N(\text { weighted\%) }\end{array}$ & $\begin{array}{c}\mathrm{p}- \\
\text { value }^{1}\end{array}$ \\
\hline \multicolumn{4}{|l|}{ Age } \\
\hline$<=40$ & $8(7.5)$ & $66(92.5)$ & \multirow[t]{5}{*}{$<0.001$} \\
\hline $41-50$ & $17(18.1)$ & $64(81.9)$ & \\
\hline $51-60$ & $29(35.5)$ & $59(64.5)$ & \\
\hline $61-70$ & $63(49.4)$ & $70(50.6)$ & \\
\hline$>70$ & $127(65.8)$ & $63(34.2)$ & \\
\hline Mean $^{2} \pm S E$ & $64.8 \pm 1.0$ & $51.0 \pm 1.0$ & $<0.001$ \\
\hline \multicolumn{4}{|l|}{ Gender } \\
\hline Female & $124(32.7)$ & $197(67.3)$ & \multirow[t]{2}{*}{0.086} \\
\hline Male & $120(42.4)$ & $125(57.6)$ & \\
\hline \multicolumn{4}{|l|}{ Race } \\
\hline Non-Hispanic White & $187(36.8)$ & $235(63.2)$ & \multirow[t]{3}{*}{0.005} \\
\hline Non-Hispanic Black & $39(44.5)$ & $47(55.5)$ & \\
\hline Hispanic or Others & $18(15.9)$ & $40(84.1)$ & \\
\hline \multicolumn{4}{|l|}{ Education } \\
\hline$<$ High school & $67(33.2)$ & $102(66.8)$ & \multirow[t]{3}{*}{0.126} \\
\hline High school & $64(30.8)$ & $100(69.2)$ & \\
\hline >High school & $112(41.1)$ & $120(58.9)$ & \\
\hline \multicolumn{4}{|l|}{ Poverty income ratio $(0-5)$} \\
\hline$<=1$ & $28(19.5)$ & $74(80.5)$ & \multirow[t]{4}{*}{0.031} \\
\hline $1.1-2$ & $73(36.7)$ & $83(63.3)$ & \\
\hline $2.1-4$ & $64(39.1)$ & $82(60.9)$ & \\
\hline$>4$ & $57(40.6)$ & $60(59.4)$ & \\
\hline \multicolumn{4}{|l|}{ Marital status } \\
\hline Married or living with partner & $137(39.2)$ & $165(60.8)$ & \multirow[t]{3}{*}{0.160} \\
\hline Never married & $13(22)$ & $25(78)$ & \\
\hline Widowed, Divorced, Separated & $88(33.9)$ & $127(66.1)$ & \\
\hline
\end{tabular}

${ }^{1}$ Tested using Rao-Scott chi-square test or $t$-test.

${ }^{2}$ Weighted mean.

complex sampling design applied in NHANES using SAS 9.1 (SAS Institute, Inc., Cary, North Carolina). The weighting analytical procedures using SAS followed the instructions published on the Centers for Disease Control and Prevention (CDC) website [26].

\section{Results}

As seen in Figure 1, around 50.6\% of cancer survivors smoked regularly prior to their cancer diagnosis and only one third of them (36.1\%) quit smoking after their cancer diagnosis. In other words, two thirds of cancer survivors $(63.9 \%)$ who smoked regularly prior to their cancer diagnosis continued to smoke. The quit smoking status of cancer survivors and demographic variables were shown in Table 1. Quit smoking rate increased as age increased among cancer survivors. Compared with cancer survivors without quit smoking behavior, cancer survivors who quit smoking after cancer diagnosis were most often older (mean \pm standard error $(\mathrm{SE})=64.8 \pm 1.0$ vs. $51.0 \pm 1.0$ years old). Cancer survivors who were Hispanic or other minorities and with low income (with poverty income ratio $<=1$ ) tended to have lower quit smoking rates.

Table 2 shows the univariate results of risk factors by the quit smoking status. Compared with cancer survivors without quit smoking behavior, cancer survivors who quit smoking after cancer diagnosis had older smoking initiation age (mean $\pm \mathrm{SE}=18.5 \pm 0.4$ vs. $17.3 \pm 0.3$ years old), longer smoking year (mean $\pm \mathrm{SE}=38.1 \pm 1.0$ vs. $33.7 \pm 1.0$ years), longer cancer year (mean $\pm \mathrm{SE}=17.0 \pm$ 
Table 2 Risk factors by quit smoking status among cancer survivors who regularly smoked prior to cancer diagnosis

\begin{tabular}{lcccc}
\hline Characteristic & $\begin{array}{c}\text { Quit } \\
(\mathrm{n}=244)\end{array}$ & & $\begin{array}{c}\text { Not quit } \\
(\mathrm{n}=322)\end{array}$ & $\begin{array}{c}\mathrm{p}- \\
\text { value }^{1}\end{array}$ \\
\cline { 2 - 3 } & $\begin{array}{c}\mathrm{N} \\
\text { (weighted\%) }^{1}\end{array}$ & $\begin{array}{c}\mathrm{N} \\
\text { (weighted\%) }^{1}\end{array}$ \\
\hline
\end{tabular}

\section{Smoking related factors}

Smoking initiation age

$$
\text { Mean }^{2} \pm \text { SE }
$$

Years smoking

Mean $^{2} \pm$ SE

Years of quit smoking after cancer diagnosis

Mean $^{2} \pm$ SE

Cancer related factors

Cancer year

Mean \pm SE

First cancer diagnosis age

Mean $^{2} \pm$ SE

Smoking-related cancer ${ }^{3}$

No

Yes

Body weight related factors

BMI

$$
\begin{aligned}
& \text { Underweight \& normal }(<25) \\
& \text { Overweight (25-29.9) } \\
& \text { Obese }(>=30)
\end{aligned}
$$

How do you consider your weight

Overweight

Underweight

About the right weight

Heath behavioral related factors

Vigorous activity over past 30 days

No

Yes

Days of 5 or more drinks in 12 months

$$
\begin{aligned}
& 0 \\
& 1-4 \\
& 5 \text { or more }
\end{aligned}
$$

\section{Health status related factors}

Number of disease ever have $^{4}$

\begin{tabular}{|c|c|}
\hline $143(41.1)$ & 153 (58.9) \\
\hline $22(26)$ & $41(74)$ \\
\hline $3(30.7)$ & $126(69.3)$ \\
\hline
\end{tabular}

0

\begin{tabular}{|c|c|}
\hline $220(38)$ & $278(62)$ \\
\hline $24(26)$ & $44(74)$ \\
\hline
\end{tabular}

$1-2$

\begin{tabular}{|c|c|}
\hline 95 (34.9) & $125(65.1)$ \\
\hline $10(20.4)$ & 37 (79.6) \\
\hline $18(33.4)$ & 29 (66.6) \\
\hline
\end{tabular}

3 and up

\begin{tabular}{|c|c|}
\hline $64(28.2)$ & $116(71.8)$ \\
\hline 31 (39.1) & 157 (60.9) \\
\hline 49 (44.2) & 49 (55.8) \\
\hline
\end{tabular}

\section{$85(30.2) \quad 147(69.8) \quad 0.083$ \\ $87(41.7) \quad 89(58.3)$ \\ $70(40.4) \quad 78(59.6)$}

\begin{tabular}{|c|c|c|}
\hline $0-3$ & $73(28.9)$ & $133(71.1) \quad 0.048$ \\
\hline $4-9$ & 87 (37.9) & 109 (62.1) \\
\hline$>=10$ & $84(45)$ & $79(55)$ \\
\hline
\end{tabular}

Table 2 Risk factors by quit smoking status among cancer survivors who regularly smoked prior to cancer diagnosis (Continued)

Number of times receive

healthcare over past year

${ }^{1}$ Tested using Rao-Scott chi-square test or $t$-test.

${ }^{2}$ Weighted mean.

${ }^{3}$ Based on American Cancer Society.

${ }^{4}$ Including 10 diseases: Arthritis, congestive heart failure, coronary heart disease, angina/angina pectoris, heart attack, stroke, emphysema, chronic bronchitis, liver condition, thyroid.

0.8 vs. $10.5 \pm 0.7$ years), and older first cancer diagnosis age (mean $\pm \mathrm{SE}=47.9 \pm 1.0$ vs. $40.5 \pm 1.2$ years old). For weight-related factors, cancer survivors who considered themselves overweight had higher quit smoking rates after cancer diagnosis compared to those who considered themselves about the right weight or underweight (41.1\%, 30.7\% and 26\%, respectively). Those who had 3 or more diseases and received health care more than 10 times over the past year had higher quit smoking rates after cancer diagnosis. However, BMI, vigorous activity over past 30 days, days of taking 5 or more drinks in the past 12 months and smoking-related cancer type were not statistically significantly associated with quit smoking behavior among cancer survivors. As shown in Table 2, on average, cancer survivors take 8.8 years to quit after cancer diagnosis.

The associations between quit smoking and potential risk factors were analyzed using the weighted logistic regressions as shown in Table 3. The adjusted OR of quit smoking for age was $1.22(95 \% \mathrm{CI}=1.16-1.28)$. This showed that quit smoking rates increased as age increased among cancer survivors. In addition, gender and racial disparities were observed in the results after controlling for age. After adjusting age, race, BMI, years smoking and cancer type, men were $1.83(95 \% \mathrm{CI}=1.04$ $3.22, \mathrm{p}=0.037$ ) times more likely to quit than women. The adjusted OR of quit smoking for Hispanic or Others vs. Non-Hispanic White was $0.23(95 \% \mathrm{CI}=0.10-0.57$, $\mathrm{p}=0.001$ ). For weight-related behaviors, cancer survivors who were overweight $(\mathrm{OR}=1.94,95 \% \mathrm{CI}=1.18-3.19$, $\mathrm{p}=0.009) \quad$ or obese $\quad(\mathrm{OR}=1.79, \quad 95 \% \mathrm{CI}=1.01-3.17$, $\mathrm{p}=0.047$ ) were more likely to have quit smoking than those who were underweight and normal weight after cancer diagnosis. For two cancer-specific factors, smoking-related cancer type was significantly associated with quit smoking. The adjusted OR of quit smoking for smoking-related cancer vs. non-smoking-related cancer was 1.89 (95\% CI $=1.17-3.03, \mathrm{p}=0.009$ ). Quit smoking rate decreased significantly as smoking year increased 


\begin{tabular}{|c|c|c|}
\hline Characteristics & OR $(95 \% \mathrm{Cl})$ & $\mathrm{p}$-value \\
\hline Age & $1.22(1.16-1.28)$ & $<.0001$ \\
\hline \multicolumn{3}{|l|}{ Gender } \\
\hline Female & 1 & \\
\hline Male & $1.83(1.04-3.22)$ & 0.037 \\
\hline \multicolumn{3}{|l|}{ Race } \\
\hline Non-Hispanic White & 1 & \\
\hline Non-Hispanic Black & $1.59(0.79-3.20)$ & 0.192 \\
\hline Hispanic or Others & $0.23(0.10-0.57)$ & 0.001 \\
\hline \multicolumn{3}{|l|}{ BMI } \\
\hline Underweight \& normal $(<25)$ & 1 & \\
\hline Overweight (25-29.9) & $1.94(1.18-3.19)$ & 0.009 \\
\hline Obese $(>=30)$ & $1.79(1.01-3.17)$ & 0.047 \\
\hline Years smoking & $0.86(0.82-0.91)$ & $<.0001$ \\
\hline \multicolumn{3}{|l|}{ Smoking-related cancer } \\
\hline No & 1 & \\
\hline Yes & $1.89(1.17-3.03)$ & 0.009 \\
\hline
\end{tabular}

after adjusting for other factors. The adjusted OR of quit smoking for 1-year increments of smoking year was 0.86 (95\% CI $=0.82-0.91)$.

\section{Discussion}

This study showed that about $63.9 \%$ of cancer survivors continued to smoke after their cancer diagnosis. The smoking prevalence among cancer survivors was presented in several studies $[12,27,28]$. Hewitt et al. analyzed data from The National Health Interview Survey 1998-2000 and found that the prevalence of current smoking among cancer survivors was high: about $20 \%$ of cancer survivors are current smokers [29]. Hakins et al. analyzed 7,903 cancer survivors at 3, 6 and 11 years after diagnosis and found that only $7.5 \%$ of survivors reported avoiding cigarettes more frequently since diagnosis [28]. The major difference between this study and the previous studies is that this study excluded cancer survivors who were non-smokers and those who quit smoking before cancer diagnosis in our primary analyses for evaluating factors associated with the quit smoking behavior. As shown in Figure 1, this study showed that about $40 \%$ of cancer survivors were non-smokers and that about half of smokers (49.4\%) quit smoking before cancer diagnosis. These two groups are not targeted for smoking cessation programs for cancer survivors. Thus, this study provided more specific information about who did not quit smoking after cancer diagnosis, which can provide valuable information for designing smoking cessation programs for cancer survivors. For total cancer survivors, no matter smoking status during their cancer diagnosis, the smoking prevalence is consistent with the previous studies as well $[14,15,21]$.

It is important to know that quitting smoking is very difficult even for those cancer patients who perceived risk of cancer. This study showed that whether cancer was smoking-related or non-smoking related, about twothirds (64\%) of cancer survivors continued to smoke after their cancer diagnosis. The quit smoking rates were similar between individuals with smoking-related cancer and those with non-smoking-related cancer (Table 2). In the multivariable model (Table 3), smoking-related cancer (such as lung, cervix and kidney cancer) was positively associated with quit smoking. This apparently inconsistent result was primarily due to age effect. We observed that the individuals with non-smoking-related cancer (mean age $\pm \mathrm{SE}=57.8 \pm 1.1$ ) were significantly older than those with smoking-related cancer (mean age $\pm \mathrm{SE}=53.6 \pm 1.3$, $\mathrm{p}$-value $=0.013$ ). Among cancer survivors with age 51-70 years old, those with a smokingrelated cancer were more likely to quit smoking than those without a smoking-related cancer $(53.4 \%$ vs. $36.1 \%$, p-value $=0.013)$. However, the associations between cancer type and quit smoking were not significant in other age subgroups ( $\mathrm{p}$-value $=0.816$ for age $<=50$, and $p$-value $=0.793$ for age $>70$ ). Thus, the effect of smoking-related cancer was confounded by the age effect in the univariate analysis.

Patterson et al. used data from the 2003 National Cancer Institute's Health Information National Trends Survey [30] and found that smokers who had higher levels of perceived cancer risk were more likely to report intention to quit. The associations between cancer type and the quit smoking behavior observed in this study are consistent with the findings from the previous studies in general $[11,12,14]$. Cancer survivors who had lung cancer have had higher quit smoking rates [14]. This study shows that cancer survivors who had smokingrelated cancer are two times more likely to quit than those who had non-smoking-related cancer. This population may perceive higher risk of cancer than nonsmoking-related cancer survivors. However, only $36 \%$ of smoking-related cancer survivors quit smoking after cancer diagnosis. In other words, those who perceived higher risk of cancer were not able to quit or did not want to quit. Cancer patients, regardless of smokingrelated cancer or not, should quit smoking because of the health consequences of cigarette smoking. To increase quitting among cancer survivors, cessation programs should stress the relevance of smoking to cancer (increase perceived susceptibility/risk of not quitting and perceived benefits of quitting) [31-34].

Gender and racial disparities were observed after controlling for age and poverty-income ratio. Gender was not significantly associated with quit smoking in univariate 
analysis, but after adjusting for other variables, the multivariate analysis showed that males are more likely to quit after cancer diagnosis than females. The quit smoking behavior after cancer diagnosis among these populations is less clear in the previous studies. Our study showed that Hispanic or Others were less likely to quit smoking than Whites after cancer diagnosis. In general, Hispanics (15.8\%) had a lower prevalence of smoking than nonHispanic blacks (21.3\%) and non-Hispanic whites (22.0\%) [35]. Latino smokers tend to smoke fewer cigarettes per day, are more likely to attempt to quit and less likely to be advised to quit by health care providers compared to nonLatino Whites [36-39]. Although Hispanics experience lower incidence and mortality rates than non-Hispanics for most common cancers [40], incidence and mortality from these cancers can be improved by appropriate cancer prevention and control approaches such as earlier screening, increased access to health care and tobacco cessation [41]. Despite gender and racial disparities among cancer survivors, age is an important factor associated with smoking cessation behaviors. Our study showed that quit smoking rates increased as age increased among cancer survivors [14]. Also, cancer survivors who had longer years smoking may be more addicted and could not quit as easily.

Although a study found that the majority of cancer survivors who smoke are likely to engage in multiple unhealthful lifestyle behaviors [23], our study showed that vigorous activity and alcohol consumption were not significantly associated with quit smoking behaviors among cancer survivors who smoked prior to cancer diagnosis. This may be due to the study population being smokers, a sub-group with unhealthy behaviors. Although quitting smoking is a relatively healthy behavior for smokers, the associations between this behavior and other risky or healthy behaviors may be different for the general population group. After controlling for demographic and other risk factors, however, BMI status was significantly associated with quitting smoking. Cancer survivors who were obese or overweight were more likely to have quit smoking than those who were underweight and normal weight after cancer diagnosis. However, it is possible that after they quit smoking they gained weight $[42,43]$. Researchers have suggested that a diagnosis of cancer is a valuable moment to encourage patients to quit smoking [16]. Our study results suggest that smoking cessation varies across demographic factors, BMI, year of smoking and smokingrelated cancer. The higher priority group of quitters among cancer survivors is younger, female, Hispanic or Other minorities, underweight or normal, with longer smoking history, and with non-smoking-related cancer.

The potential contribution of the paper is limited for several reasons. First, the cross-sectional design in the NHANES limits conclusions about the causal relationship of risk factors and quit smoking behaviors. Second, the self-reported cancer histories, smoking statuses and demographic characteristics used in this study may have some biases. Third, although all analyses were weighted to account for the complex sampling design applied in NHANES, our results may not represent the whole of US cancer survivors who smoked prior to cancer diagnosis due to the survey limitations. The sample does not include persons residing in nursing homes, members of the armed forces, institutionalized persons, or U.S. nationals living abroad.

\section{Conclusion}

Despite these limitations, this study uses the past 10 years' national data to provide novel and important contributions for the profile of cancer survivors who continued smoking after cancer diagnosis. The results show that two-thirds of cancer survivors continued smoking after cancer diagnosis and smoking cessation behavior is highly associated with survivor's age and years smoking. Cigarette smoking is so addictive that even some smoking-related cancer patients cannot quit smoking after learning they need to quit or perceive risk for dying. It has been indicated that identifying who is more likely to continue smoking after cancer diagnosis is important for developing smoking cessation interventions [44]. According to the 2008 update to Treating Tobacco Use and Dependence, a Public Health Service-sponsored Clinical Practice Guideline(PHS), several effective treatments exist. Tobacco use treatments such as counseling, medication and motivational counseling have been shown to be effect among cancer patients [20]. PHS suggests that more intensive cessation interventions will substantially increase the intervention effects. It has been shown that smoking cessation should be made more accessible to lower socioeconomic groups for better successful quitting rates and extend abstinence periods [45]. Although PHS clinical practice guideline recommends several effective tobacco treatments for cancer survivors, this study suggests that the future interventions for quitting smoking among cancer survivors should target those who are younger, female, Hispanic or other minorities, underweight or normal weight, with longer smoking history, and with nonsmoking-related cancer. In order to design effective smoking cessation treatments and understand what types on of treatments and duration would be better utilized among cancer survivors, it would be necessary to carry out qualitative interviews customized for different cancer patient groups in the future.

\section{Abbreviations}

NHANES: National health and nutrition examination surveys; CDC: Centers for disease control and prevention; NCHS: National center for health statistics; BMI: Body mass index; Cl: Confidence intervals; OR: Odds ratio. 


\section{Competing interests}

The authors declare that they have no competing interests.

\section{Authors' contributions}

TS Tseng originated the idea and drafted the article. HY Lin analyzed the data and revised the article. S Moody-Thomas and MY Martin reviewed and revised the article. T Chen helped interpret the results and revise the article. All authors read and approved the final manuscript.

\section{Author details}

${ }^{1}$ School of Public Health, Louisiana State University Health Sciences Center, 2020 Gravier Street, New Orleans, LA 70112, USA. ${ }^{2}$ Biostatistics Department, H. Lee Moffitt Cancer Center \& Research Institute, 12902 Magnolia Drive, Tampa, FL 33612, USA. ${ }^{3}$ Division of Preventive Medicine, University of Alabama at Birmingham, 1717 11th Avenue South, Birmingham, AL 35205, USA. ${ }^{4}$ Department of Community Health Sciences, Tulane University, 1440 Canal Street, New Orleans, LA 70112, USA.

Received: 18 October 2011 Accepted: 20 August 2012

Published: 14 September 2012

\section{References}

1. Ganz PA: Survivorship: adult cancer survivors. Prim Care 2009, 36(4):721-741.

2. Centers for Disease Control and Prevention: Cancer survivors - United States, 2007. MMWR Morb Mortal Wkly Rep 2011, 60(9):269-272.

3. Centers for Disease Control and Prevention: Cancer survivorship--United States, 1971-2001. MMWR Morb Mortal Wkly Rep 2004, 53(24):526-529.

4. Valdivieso M, Kujawa AM, Jones T, Baker LH: Cancer survivors in the United States: a review of the literature and a call to action. Int J Med Sci 2012, 9(2):163-173.

5. Demark-Wahnefried W, Morey MC, Sloane R, Snyder DC, Cohen HJ: Promoting healthy lifestyles in older cancer survivors to improve health and preserve function. J Am Geriatr Soc 2009, 57(Suppl 2):S262-264.

6. Morey MC, Snyder DC, Sloane R, Cohen HJ, Peterson B, Hartman TJ, Miller P, Mitchell DC, Demark-Wahnefried W: Effects of home-based diet and exercise on functional outcomes among older, overweight long-term cancer survivors: RENEW: a randomized controlled trial. JAMA 2009, 301(18):1883-1891.

7. Rabin C, Politi M: Need for health behavior interventions for young adult cancer survivors. Am J Health Behav 2010, 34(1):70-76.

8. Gritz ER, Demark-Wahnefried W: Health behaviors influence cancer survival. J Clin Oncol 2009, 27(12):1930-1932.

9. Coups EJ, Park BJ, Feinstein MB, Steingart RM, Egleston BL, Wilson DJ, Ostroff JS: Physical activity among lung cancer survivors: changes across the cancer trajectory and associations with quality of life. Cancer Epidemiol Biomarkers Prev 2009, 18(2):664-672.

10. Underwood JM, Townsend JS, Stewart SL, Buchannan N, Ekwueme DU, Hawkins NA, Li J, Peaker B, Pollack LA, Richards TB, et al: Surveillance of demographic characteristics and health behaviors among adult cancer survivors-Behavioral Risk Factor Surveillance System, United States, 2009. MMWR Surveill Summ 2012, 61(1):1-23.

11. Mayer DK, Terrin NC, Menon U, Kreps GL, McCance K, Parsons SK, Mooney KH: Health behaviors in cancer survivors. Oncol Nurs Forum 2007, 34(3):643-651.

12. Bellizzi KM, Rowland JH, Jeffery DD, McNeel T: Health behaviors of cancer survivors: examining opportunities for cancer control intervention. J Clin Oncol 2005, 23(34):8884-8893.

13. Shinn EH, Swartz RJ, Thornton BB, Spiess PE, Pisters LL, Basen-Engquist KM: Testis cancer survivors' health behaviors: comparison with age-matched relative and demographically matched population controls. J Clin Oncol 2010, 28(13):2274-2279.

14. Tseng TS, Lin HY, Martin MY, Chen T, Partridge EE: Disparities in smoking and cessation status among cancer survivors and non-cancer individuals: a population-based study from National Health and Nutrition Examination Survey. J Cancer Surviv 2010, 4(4):313-321.

15. Coups EJ, Ostroff JS: A population-based estimate of the prevalence of behavioral risk factors among adult cancer survivors and noncancer controls. Prev Med 2005, 40(6):702-711.
16. Gritz ER, Fingeret MC, Vidrine DJ, Lazev AB, Mehta NV, Reece GP: Successes and failures of the teachable moment: smoking cessation in cancer patients. Cancer 2006, 106(1):17-27.

17. Gritz ER, Dresler C, Sarna L: Smoking, the missing drug interaction in clinical trials: ignoring the obvious. Cancer Epidemiol Biomarkers Prev 2005, 14(10):2287-2293.

18. Jensen $\mathrm{K}$, Jensen $A B$, Grau C: Smoking has a negative impact upon health related quality of life after treatment for head and neck cancer. Oral Oncol 2007, 43(2):187-192.

19. Demark-Wahnefried W, Jones LW: Promoting a healthy lifestyle among cancer survivors. Hematol Oncol Clin North Am 2008, 22(2):319-342.

20. Fiore MC JC, Baker TB, et al: Treating Tobacco Use and Dependence: 2008 Update. Clinical Practice Guideline. Edited by Department of Health and Human Services. Rockville, MD: Public Health Service; 2008.

21. Burke L, Miller LA, Saad A, Abraham J: Smoking behaviors among cancer survivors: an observational clinical study. J Oncol Pract 2009, 5(1):6-9.

22. Humpel N, Magee C, Jones SC: The impact of a cancer diagnosis on the health behaviors of cancer survivors and their family and friends. Support Care Cancer 2007, 15(6):621-630.

23. Butterfield RM, Park ER, Puleo E, Mertens A, Gritz ER, Li FP, Emmons K: Multiple risk behaviors among smokers in the childhood cancer survivors study cohort. Psychooncology 2004, 13(9):619-629.

24. National Center for Health Statistics: National Health and Nutrition Examination Survey. [http://www.cdc.gov/nchs/nhanes.htm]

25. American Cancer Society: Cancer Facts \& Figures 2012. Atlanta, Georgia: American Cancer Society; 2012.

26. National Center for Health Statistics: Continuous NHANES Web Tutorial: NHANES Analyses; [http://www.cdc.gov/nchs/tutorials/NHANES/ NHANESAnalyses/NHANES_Analyses_intro.htm]

27. Eakin EG, Youlden DR, Baade PD, Lawler SP, Reeves MM, Heyworth JS, Fritschi L: Health behaviors of cancer survivors: data from an Australian population-based survey. Cancer Causes Control 2007, 18(8):881-894.

28. Hawkins NA, Smith T, Zhao L, Rodriguez J, Berkowitz Z, Stein KD: Healthrelated behavior change after cancer: results of the American cancer society's studies of cancer survivors (SCS). J Cancer Surviv 2010, 4(1):20-32.

29. Hewitt M, Rowland JH, Yancik R: Cancer survivors in the United States: age, health, and disability. J Gerontol A Biol Sci Med Sci 2003, 58(1):82-91.

30. Patterson F, Wileyto EP, Segal J, Kurz J, Glanz K, Hanlon A: Intention to quit smoking: role of personal and family member cancer diagnosis. Health Educ Res 2010, 25(5):792-802.

31. Garces-Palacio IC, Scarinci IC: Factors associated with perceived susceptibility to cervical cancer among latina immigrants in alabama. Matern Child Health J 2012, 16(1):242-248.

32. Okoli CT, Richardson CG, Ratner PA, Johnson JL: Non-smoking youths' "perceived" addiction to tobacco is associated with their susceptibility to future smoking. Addict Behav 2009, 34(12):1010-1016.

33. McKee SA, O'Malley SS, Salovey P, Krishnan-Sarin S, Mazure CM: Perceived risks and benefits of smoking cessation: gender-specific predictors of motivation and treatment outcome. Addict Behav 2005, 30(3):423-435.

34. Waters EA, Arora NK, Klein WM, Han PK: Perceived risk, trust and health-related quality of life among cancer survivors. Ann Behav Med 2010, 39(1):91-97.

35. Centers for Disease Control and Prevention: Cigarette smoking among adults and trends in smoking cessation - United States, 2008. MMWR Morb Mortal Wkly Rep 2009, 58(44):1227-1232.

36. Bock BC, Niaura RS, Neighbors CJ, Carmona-Barros R, Azam M: Differences between Latino and non-Latino White smokers in cognitive and behavioral characteristics relevant to smoking cessation. Addict Behav 2005, 30(4):711-724.

37. Rogers RG, Crank J: Ethnic differences in smoking patterns: findings from NHIS. Public Health Rep 1988, 103(4):387-393.

38. Houston TK, Scarinci IC, Person SD, Greene PG: Patient smoking cessation advice by health care providers: the role of ethnicity, socioeconomic status, and health. Am J Public Health 2005, 95(6):1056-1061.

39. Levinson AH, Perez-Stable EJ, Espinoza P, Flores ET, Byers TE: Latinos report less use of pharmaceutical aids when trying to quit smoking. Am J Prev Med 2004, 26(2):105-111.

40. American Cancer Society: Cancer Facts \& Figures for Hispanic/Latinos 2006-2008. Atlanta, Georgia: American Cancer Society; 2007. 
41. Ramirez AG, Gallion KJ, Suarez L, Giachello AL, Marti JR, Medrano MA, Perez-Stable EJ, Talavera GA, Trapido EJ: A national agenda for Latino cancer prevention and control. Cancer 2005, 103(11):2209-2215.

42. Filozof C, Fernandez Pinilla MC, Fernandez-Cruz A: Smoking cessation and weight gain. Obes Rev 2004, 5(2):95-103.

43. Eisenberg D, Quinn BC: Estimating the effect of smoking cessation on weight gain: an instrumental variable approach. Health Serv Res 2006, 41(6):2255-2266.

44. de Moor JS, Elder K, Emmons KM: Smoking prevention and cessation interventions for cancer survivors. Semin Oncol Nurs 2008, 24(3):180-192.

45. Marti J: Successful smoking cessation and duration of abstinence-an analysis of socioeconomic determinants. Int J Environ Res Public Health 2010, 7(7):2789-2799.

doi:10.1186/1471-2458-12-784

Cite this article as: Tseng et al:: Who tended to continue smoking after cancer diagnosis: the national health and nutrition examination survey 1999-2008. BMC Public Health 2012 12:784.

\section{Submit your next manuscript to BioMed Central and take full advantage of:}

- Convenient online submission

- Thorough peer review

- No space constraints or color figure charges

- Immediate publication on acceptance

- Inclusion in PubMed, CAS, Scopus and Google Scholar

- Research which is freely available for redistribution 